\title{
Unilateral Duplication of Optic Canal: A Case Report
}

\author{
Vanitha ${ }^{1}$, Taqdees Fatima ${ }^{2}$,H. S. Kadlimatti ${ }^{3}$ \\ ${ }^{1}$ (Department of Anatomy, ESIC Medical College Gulbarga/ Rajiv Gandhi university of health \\ Sciences, Karnataka, India) \\ ${ }^{2}$ (Department of Anatomy, ESIC Medical College Gulbarga/ Rajiv Gandhi university of health \\ Sciences, Karnataka, India) \\ ${ }^{3}$ (Department of Anatomy, ESIC Medical College Gulbarga/ Rajiv Gandhi university of health \\ Sciences, Karnataka, India)
}

\begin{abstract}
Optic canal is formed by two roots of lesserwing and body of sphenoid bone. It transmits optic nerve, ophthalmic artery and periarterial sympathetic plexus. During demonstration classes for undergraduate students we observed optic canal of left orbit of the adult skull, showing a thin spicule of bone which divided optic canal into two. Unilateral presence of duplicated optic canal is very rare. This case report may be useful for surgeons and radiologists.
\end{abstract}

Keywords: Duplication, duramater, optic canal, ossification,

\section{Introduction}

Optic canal is formed by the two roots of lesser wing and body of sphenoid bone. Anterior root of lesser wing of sphenoid is flat and posterior root is thick, triangular. The optic canal lies between these roots and connects the orbit to the middle cranial fossa. It is traversed by the optic nerve and its meningeal coverings, the ophthalmic artery and by the branches from the periarterial sympathetic plexus. The artery and nerve are separated by a layer of dense connective tissue which may occasionally be ossified to result in the duplication of the optic canal.

\section{Case report}

During osteology demonstration classes for undergraduate medical students we observed that a thin spicule of bone dividing the optic canal into postero-medial large optic canal proper and infero-lateral small canal ,accessory optic canal ,thus forming duplication of optic canal on left side[figure:1]. Right side optic canal was normal.

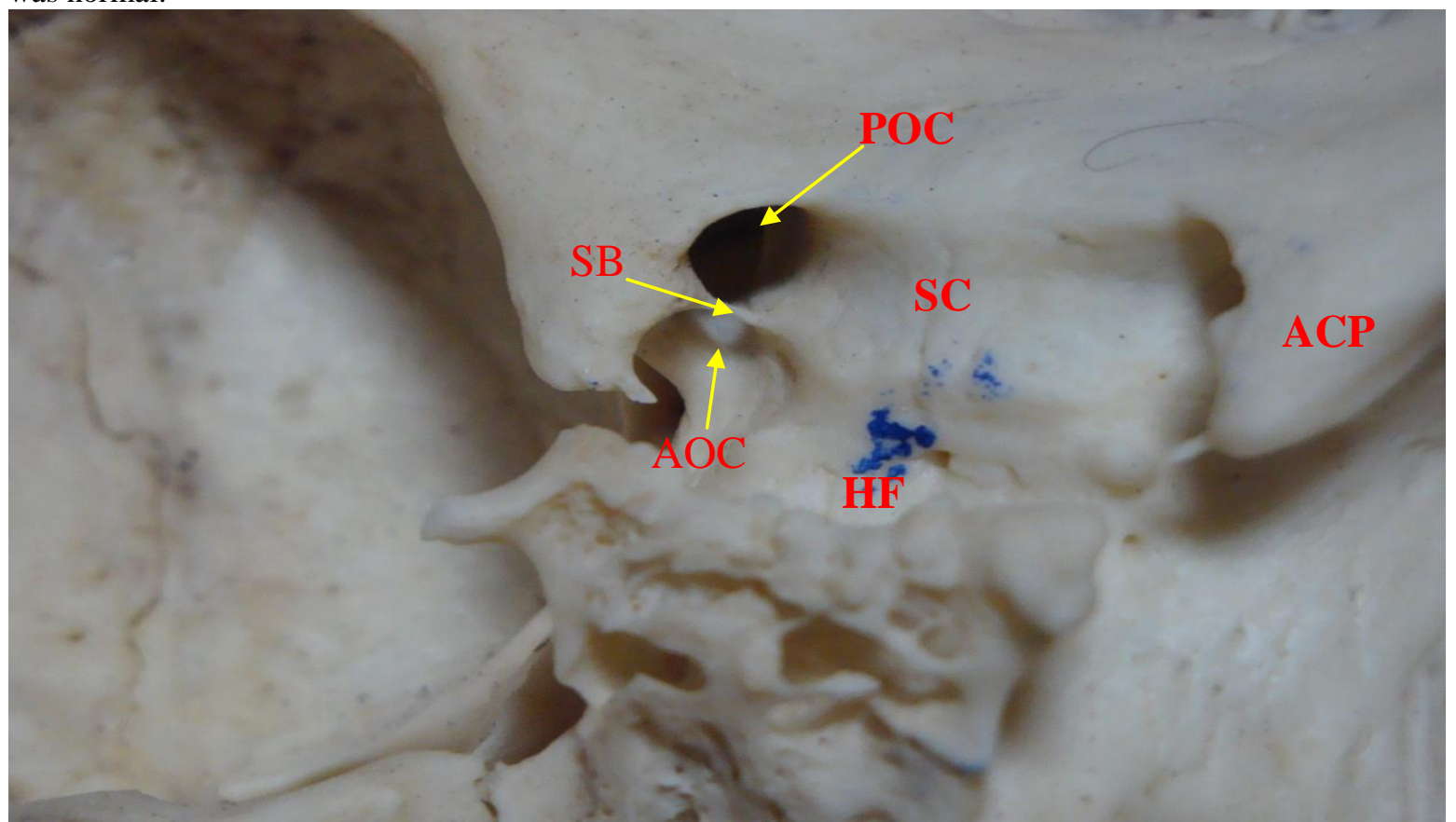

Figure 1; showing spicule of bone [SB] dividing optic canal into posteromedial large ,proper optic canal [POC] and infero lateral small canal,Accessory Optic Canal [AOC] on left side. SC-Sulcus Chiasmaticus, HFHypophyseal Fossa, ACP-Anterior Clinoid Process. 


\section{Discussion}

In this case left side optic canal was showing duplication. Unilateral duplication is very rare, $1 \%$ of unilateral duplication of optic canal out of is noticed in a study of 200 bony orbits [1]. Ghai et al., studied 194 skulls, in that 5(2.57\%) showed duplication of optic canal. Out of these three skulls showed bilateral (1.5\%) and two skulls showed left sided unilateral (1.03\%) [2]. Choudhry et al.,observed optic canal in three skulls, in that two were bilateral and one was unilateral and postulated that this bony projection when large, could result in the division of optic canal into two parts, upper larger for the optic nerve and the lower smaller for the ophthalmic artery[3]. Patil V. et al., noticed $11(2.75 \%)$ duplicated optic canal out of 400 human skulls. The duplication was bilateral in $3(0.94 \%)$ and unilateral in $8(2.5 \%)$ skulls[4].Singh M.studied 435 Japanese skulls out of which 13 (4\%)skulls showed duplication of the optic canal of which 7(1.6\%) were bilateral and 6 unilateral (1.38\%) 4 on right and 2 on left [5].Embryological basis for the formation of optic canal is not clear, Le double (1903) said,the division of optic canal is due to ossification of the duramater covering the optic nerve. This may not be probable as many cases reported were in children [6]. Augier (1931) suggested that duplication of optic canal represents the persistence of a foramen "lee trou metoptique". He opined that accessory foramen may be due to presence of an aberrant ophthalmic vein as a shallow groove leads to the site of cavernous sinus suggesting it might transmit inferior ophthalmic vein[7]. Wolf speculated that a band of connective or fibrous tissue which separates optic nerve and ophthalmic artery might be ossified leading to duplication of optic canal [8].Keyes (1935) proposed that a large bony projection in the inferolateral wall of optic canal duplicates the optic canal [9]. The duplication optic canal is developmental in origin. This duplication is dependent upon development of lower root of lesser wing of sphenoid bone. The anomalous development may lead to duplication and not due to ossification. The larger canal transmits optic nerve with meninges and the smaller canal transmits ophthalmic artery [10].

\section{Conclusion}

Knowledge about unilateral duplication of optic canal variations useful during interventional procedures of optic canal and surrounding regions, especially during endoscopic tumor removal and optic nerve decompression. They cana lso evoke confusion during the interpretation and the evaluation of the CT scans or the X-rays of the spheno ethmoid region.

\section{References}

[1]. Vijaykumar Shankar Shinde, Raveendra Patil1, Channabasanagouda1and Mallikarjun M:Study of duplication of optic canal in hundred dry human skull bones;IJBR (2013) 04 (11); pp.633-635

[2]. Rashmi Ghai, Priti Sinha,Jaba Rajguru,Shilpi Jain,Satyam Khare,Mukesh Singla: duplication of optic canal in human skulls; journal of anatomical society of India 61(1)pp.33-36(2012).

[3]. Rewa Choudhry, S.Choudhry and C.Anand: Duplication of optic canals in human skulls: J. Anat. (1988), 159, pp. 113-116

[4]. Girish V. Patil, Sanjeev Kolagi, Padmavathi G., G.B. Rairam: the Duplication of the Optic Canals in Human Skulls;Journal of Clinical and Diagnostic Research. 2011 June, Vol-5(3): 536-537

[5]. 5.Mandavi Singh.; duplication of optic canal in adult Japanese human skulls;journal of Anatomical society of India; 54(2); 19(2005)

[6]. Le Double AF: Traite'des variations des os du crane de l' home. Paris: Vigol Fre'res.1935:1903.372.

[7]. Augier M: Sequelette cephalique, in Poirier and chapy'schapy's. Traite d' Anatomic humaine. 1st ed. Paris.234.246.248.

[8]. Wolf E. Anatomy of the eye and orbit. 7th eded. Vol 15. London; HK Lewis. 1976:65.69.

[9]. Keyes JEL. Observation on four thousand optic foramina. Albrecht V. Graefes.Arch furopthalmologie.1935; 13:538.568.

[10]. Leon KE. Embryology of normal optic canal and its anomalies an anatomic and roentgenographic study. Investigative radiology. $1996 ; 1(5): 346.362$. 